\title{
Analysis of esterase enzyme activity in adults of the major malaria vector Anopheles funestus
}

\author{
Yael Leah Dahan-Moss ${ }^{1,2^{*}}$ and Lizette Leonie Koekemoer ${ }^{1,2}$
}

\begin{abstract}
Background: Anopheles funestus is a major vector of malaria in sub-Saharan Africa. In order to apply effective control measures against this vector, it is necessary to understand the underlying physiological factors that play a critical role in its development, reproduction, fertility and susceptibility to insecticides. One enzyme family involved in the above mentioned biological pathways is the esterases. The aim of this study was to analyse esterase activity levels at different ages during the life-span of adult Anopheles funestus Giles in order to better understand the complex biological processes in this species.

Methods: Isoenzyme electrophoresis (IEE) was used to examine the esterase activity in laboratory colonised An. funestus adults aged between $2 \mathrm{~h}(\mathrm{~h})$ and 30 days post eclosion as well as in wild An. funestus adults aged between $2 \mathrm{~h}$ and 15 days post eclosion. Esterase activity was quantified by densitometry analysis of the IEE gels. Esterases were classified according to their activity inhibition by organic phosphates, eserine sulphate and sulphydryl reagents.

Results: Nine esterases IEE profiles were common to both the laboratory colonised and wild An. funestus adults. These esterases were further divided into acetylesterases, arylesterases, carboxylesterases and acetylcholinesterase. The activity level of certain specific esterases was primarily influenced by age and/or gender.

Conclusions: The information from this study contributes towards the general understanding of esterase enzyme activity variation in adults of a major malaria vector An. funestus. This variation likely carries physiological and adaptive significance and may influence specific characteristics, such as reproductive fitness and insecticide resistance that are epidemiologically important.
\end{abstract}

Keywords: Anopheles funestus, Isoenzyme electrophoresis, Esterase classification

\section{Background}

Malaria is a devastating vector-borne disease, which in 2015 resulted in an estimated 438,000 deaths worldwide, the majority of which occurred in sub-Saharan Africa [1]. Anopheles funestus is a major malaria vector in subSaharan Africa and is capable of causing severe epidemics such as that experienced in South Africa from 1996 to $2000[2,3]$. During the past decade, several studies have highlighted the increasing prevalence of resistance to insecticides in An. funestus populations [4-6] and the

\footnotetext{
* Correspondence: yaeld@nicd.ac.za

${ }^{1}$ Wits Research Institute for Malaria, School of Pathology, Faculty of Health Sciences, University of the Witwatersrand, Johannesburg, South Africa ${ }^{2}$ Centre for Opportunistic, Tropical and Hospital Infections, National Institute for Communicable Diseases, a Division of the National Health Laboratory Service, Sandringham, Johannesburg, South Africa
}

resultant threat posed to effective vector control. However, there have been few studies covering other important aspects of An. funestus s.s. biology.

The application of effective vector control measures against insect disease vectors is best achieved using an understanding of the reproductive, behavioural and ecological characteristics of each species as well as the underlying physiological processes that govern these characteristics. Enzyme expression, including variation in expression by life stage and age, is important in the mediation of these characteristics. The esterase family consists of numerous enzymes all of which catalyse the hydrolysis of esters. In insects, esterases are linked with critical physiological roles such as behaviour [7], development [8-10], insecticide resistance [11-13], and reproduction [14]. 
Esterases in arthropods including Anopheles can be classified according to alpha or beta esterases depending on their ability to hydrolyze the substrates alpha- and betanaphthyl acetate respectively $[11,15,16]$. In addition, esterases can be characterized according to inhibition criteria $[13,15,17,18]$. This is based on the use of organophosphates to inhibit carboxylesterase activity, organophosphates and eserine sulphate to inhibit cholinesterase activity and sulphydryl reagents to inhibit arylesterase activity. The acetylesterases are not inhibited by the above-mentioned compounds [13].

Esterase related studies in $A n$. funestus adults have been restricted to their role in insecticide resistance and establishing the presence of a sex-limited esterase in the male accessory glands [19-21]. Increased esterase activity was recorded in pyrethroid and carbamate resistant An. funestus adults from the Tihuquine region in Mozambique [19], as well as in specimens from the Chikwawa region in Malawi which were resistant to permethrin, deltamethrin, bendiocarb and DDT [20]. In a different study relating to An. funestus esterases, Green demonstrated that there is a specific esterase that is mainly concentrated in male An. funestus accessory glands [21]. Although these studies added insights to the An. funestus physiology from an esterase perspective, it is necessary to further examine the esterase activity profile in $A n$. funestus adults to better understand biological processes in this important vector species. The aim of this study was to characterise the different esterases in the $A n$. funestus adults to provide new knowledge on this species biology and possibly its control.

\section{Methods}

\section{Laboratory colonised and wild An. funestus samples}

Samples of both laboratory-reared and wild caught $A n$. funestus s.s. females and males were used in this investigation. All were housed in the Botha de Meillon Insectary of the National Institute for Communicable Diseases (NICD), Johannesburg, and maintained under standard insectary conditions of $25 \pm 1{ }^{\circ} \mathrm{C}$ and $80 \%$ relative humidity with a $12: 12 \mathrm{~h}$ light/dark cycle and 45 min dusk/ dawn simulation. The FUMOZ laboratory colony was established in 2000 using wild-caught An. funestus material from southern Mozambique [22]. The wild $A n$. funestus material (FUZIM) was obtained from adult $A n$. funestus females collected from houses in Honde Valley, Zimbabwe $\left(18^{\circ} 25^{\prime} 19.0^{\prime \prime}\right.$ S, 32 $2^{\circ} 58^{\prime} 35.8^{\prime \prime}$ ) , in March 2014. They were transported back to the NICD and induced to lay eggs. Eggs were reared through to $F_{1}$ adults, which were used for this study.

Emerging FUMOZ and $\mathrm{F}_{1}$ FUZIM An. funestus females and males were collected at $30 \mathrm{~min}$ intervals and placed in $2 \mathrm{~L}$ cages supplemented with a $10 \%$ sucrose solution. FUMOZ adults (aged between $2 \mathrm{~h}$ to
30 days) and FUZIM adults (aged between $2 \mathrm{~h}$ and 15 days) were removed from the cages at specific times and stored at $-70{ }^{\circ} \mathrm{C}$ until they were prepared for electrophoresis analysis. Due to the limited number of $\mathrm{F}_{1}$ FUZIM samples, only adults that were aged between $2 \mathrm{~h}$ to 15 days old were used.

\section{Isoenzyme electrophoresis}

For each time point, two An. funestus adults of each sex and from the FUMOZ and $\mathrm{F}_{1}$ FUZIM populations were homogenized in $80 \mu \mathrm{l}$ of grinding buffer (10\% sucrose, $33 \%$ Tris-Boric acid-EDTA (TBE) buffer, $\mathrm{pH}$ 8.9) [23]. The homogenates were centrifuged at $13000 \mathrm{rpm}$ for $5 \mathrm{~min}$ and $8 \mu \mathrm{l}$ of the supernatant was loaded onto a continuous non-denaturing native $7.5 \%$ polyacrylamide gel. The homogenates were electrophoresed for $3 \mathrm{~h}$ at a constant ampage of $40 \mathrm{~mA}$ with continuous cooling at $4{ }^{\circ} \mathrm{C}$. Subsequently, the gels were incubated in a soaking solution (0.1 M sodium phosphate buffer, pH 6.4, which contained $8 \%$ of alpha or beta naphthyl solution ( $2 \%$ of alpha or beta naphthyl acetate in $50 \%$ acetone)) at $37{ }^{\circ} \mathrm{C}$ for $30 \mathrm{~min}$. The gels were then stained in a soaking solution containing $0.1 \%$ Fast blue $\mathrm{R} / \mathrm{R}$ at $37{ }^{\circ} \mathrm{C}$ for $2 \mathrm{~h}$. ImageJ software [24] was used to perform densitometry analysis of the IEE gels, which provided an estimation of the esterase activity.

\section{Characterization of esterases by inhibitory assays}

The esterases were characterised according to their inhibition criteria [13]. Isoenzyme electrophoresis was performed as described above with the exception that individual gels were placed in a soaking solution containing one of the following inhibitors: p-hydroxymercuribenzoic acid sodium salt (pHMB, $1.5 \mathrm{mM}$ ); malathion (1.5 mM); eserine $(1.5 \mathrm{mM})$ and phenylmethylsulfonyl fluoride (pMSF, $1.5 \mathrm{mM}$ ). Prior to adding pHMB and pMSF to the soaking solutions, $\mathrm{pHMB}$ was dissolved in $100 \mu \mathrm{l}$ of $\mathrm{NaOH}, \mathrm{pH} 9$ and the PMSF was dissolved in $500 \mu \mathrm{l}$ of absolute ethanol (Purity (GC) $\geq 99.5 \%$ ).

\section{Results}

\section{Common esterases in the laboratory colonised and wild}

\section{An. funestus adults}

The electrophoretic pattern of the esterase activity in the An. funestus females and males from the FUMOZ colony that were aged between $2 \mathrm{~h}$ and 30 days post eclosion and the $\mathrm{F}_{1}$ FUZIM samples aged between $2 \mathrm{~h}$ and 15 days post eclosion is shown in Fig. 1. There were 9 electrophoretic bands of esterase isoenzymes on the IEE gel that were common to the FUMOZ and FUZIM samples. The esterase bands on the polyacrylamide gel were labelled EST-1 to -9 starting from the anode end of the gel (Fig. 1). 


\section{$\underline{\text { Females }}$}

\section{FUMOZ}
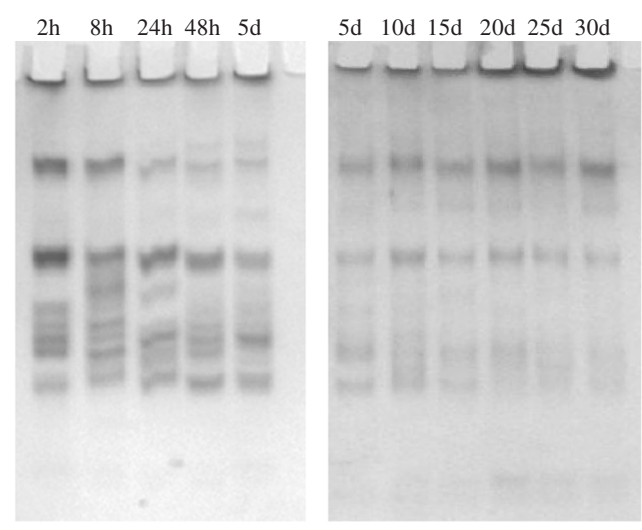

$\underline{\text { Males }}$

\section{FUMOZ}

$2 \mathrm{~h} \quad 8 \mathrm{~h} \quad 24 \mathrm{~h} \quad 48 \mathrm{~h} \quad 5 \mathrm{~d}$

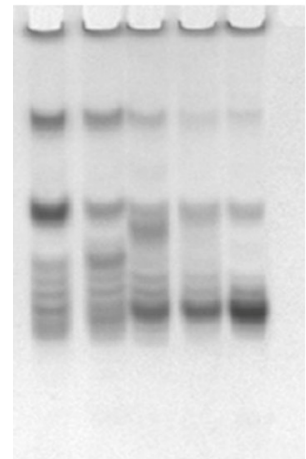

5d 10d 15d 20d 25d 30d

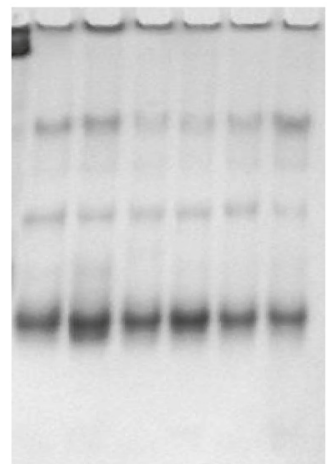

FUZIM

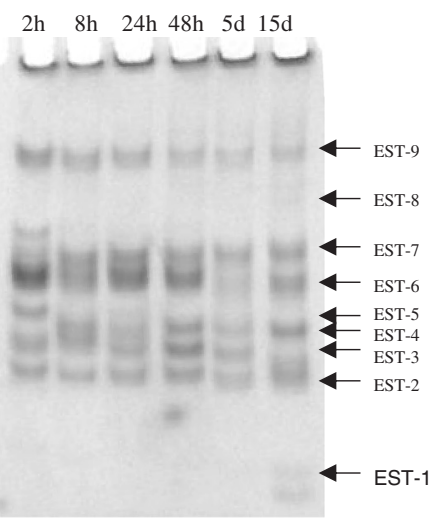

\section{FUZIM}

2h $\quad 8 \mathrm{~h} \quad 24 \mathrm{~h} \quad 48 \mathrm{~h} \quad 5 \mathrm{~d} \quad 15 \mathrm{~d}$

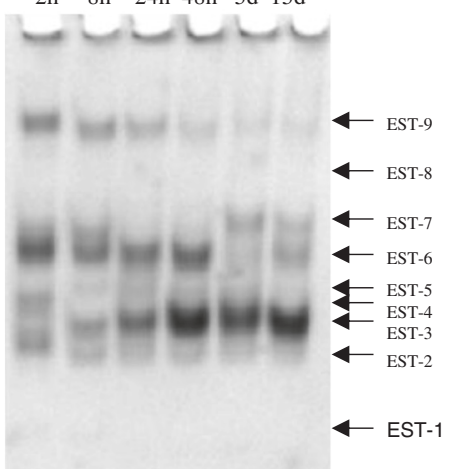

Fig. 1 IEE gels depicting the activity of esterases 1 to 9 in the adult An. funestus. The FUMOZ females and males were aged $2 \mathrm{~h}$ to 30 days post eclosion and the $\mathrm{F}_{1}$ FUZIM An. funestus females and males were aged $2 \mathrm{~h}$ to 15 days post eclosion. ( $h=$ hours old; $d=$ days old)

\section{Characterization of esterases 1 to 9}

Esterases 1 to 9 were categorized as alpha and/or beta esterases according to their ability to hydrolyse either alpha- or beta-naphthyl acetate, which is indicated by the appearance of black or red bands on the IEE gels respectively. Esterases 1 to 9 all preferentially hydrolyzed alpha-naphthyl acetate as their activity was seen as a black band on the gel that had both alpha- and betanaphthyl acetate as substrates. Esterase 2, 3, 5, 6, 7 and 9 were also able to hydrolyse beta-naphthyl acetate on a gel that had only beta-naphthyl acetate as a substrate.

The esterases were further characterized according to inhibition criterion. Esterase 1 and 8 were not inhibited by eserine sulphate, malathion or pHMB (Table 1). Esterase 2 and 4 were strongly inhibited by pHMB. Esterase 3 activity was strongly inhibited by PMSF and slightly inhibited by pHMB. Esterases 5, 6 and 7 were inhibited by both malathion and PMSF and EST-9 was
Table 1 The inhibition of An. funestus esterases 1 to 9 with specific substrates

\begin{tabular}{lllll}
\hline Esterase & Eserine & Malathion & pHMB & PMSF \\
\hline EST-1 & - & - & - & - \\
EST-2 & - & - & +++ & - \\
EST-3 & - & - & + & +++ \\
EST-4 & - & - & +++ & - \\
EST-5 & - & +++ & - & +++ \\
EST-6 & - & +++ & - & +++ \\
EST-7 & - & +++ & - & +++ \\
EST-8 & - & - & - & - \\
EST-9 & +++ & - & +++ & - \\
\hline
\end{tabular}

- = no inhibition of esterase activity, $+=$ slight inhibition of esterase activity and $+++=$ strong inhibition of esterase activity. PHMB p-

hydroxymercuribenzoic acid sodium salt; PMSF phenylmethylsulfonyl fluoride 
strongly inhibited by eserine sulphate and $\mathrm{pHMB}$ (Table 1).

\section{Analysis of esterase activity in adult An. funestus females and males}

Densitometry of the IEE gels was used for the semiquantitative analysis of the activity of the different esterases in all samples. The activity of EST-1, EST-4, EST-5, EST-6, EST-7 and EST-8 fluctuated at the different ages and sexes (Figs. 1 and 2). In contrast, EST-2, EST-3 and EST-9 showed a specific pattern of esterolytic activity that can be linked to sex and/or age (Fig. 3).

EST-2 activity was evident in each of the laboratoryreared FUMOZ females that were aged $2 \mathrm{~h}$ (h) to 30 days and the FUZIM females aged $2 \mathrm{~h}$ to 15 days (Figs. 1 and 3 ). In contrast, the activity of this esterase was not evident in the FUMOZ males aged $2 \mathrm{~h}$ to 30 days. EST-2 activity was only detectable in FUZIM males that were aged $2 \mathrm{~h}, 8 \mathrm{~h}$ and $48 \mathrm{~h}$ post eclosion. EST-2 activity was 2.4 and 7.3 fold higher in the FUZIM females aged $8 \mathrm{~h}$ and $48 \mathrm{~h}$ than males of the same age (Figs. 1 and 3).

EST-3 activity was higher in the FUMOZ males aged $24 \mathrm{~h}$ to 30 days post eclosion and FUZIM males aged $24 \mathrm{~h}$ to 15 days post eclosion versus corresponding females from the same colonies and of the same ages (Figs. 1 and 3). The activity of EST-3 ranged between 12.9 and 114.7 fold higher in FUMOZ males aged $24 \mathrm{~h}$ to 30 days in comparison to EST-3 activity in the females of the same ages. Additionally, EST-3 activity was barely detectable in the FUMOZ females aged 5 days to 30 days. The fold difference of EST-3 activity in FUZIM was between 2.7 and 14.7 higher in males aged $24 \mathrm{~h}$ to 15 days when compared to the females of the same ages. Furthermore, EST-3 activity was not detectable in FUZIM females aged 15 days post eclosion (Figs. 1 and 3). EST-3 activity in adult females from FUMOZ and FUZIM was variable (Figs. 1 and 3). In contrast, it was notable that EST-3 activity increased with age in FUMOZ (aged $2 \mathrm{~h}$ to 5 days) and FUZIM males (aged $2 \mathrm{~h}$ to $48 \mathrm{~h}$ ). The EST-3 activity was 15.1 fold higher in FUMOZ males that were 15 days old than in newly emerged males ( $2 \mathrm{~h}$ ) (Figs. 1 and 3). After 5 days the activity of EST-3 in the males was variable with the highest fold difference in activity being 1.7 (Figs. 1 and 3). Similarly, in FUZIM males EST-3 activity was not detected in newly emerged $(2 \mathrm{~h})$ males, while the increase in EST-3 activity in $48 \mathrm{~h}$ males versus $8 \mathrm{~h}$ males was 4.4 fold. After $48 \mathrm{~h}$, the highest fold difference in EST-3 activity in the FUZIM males was 1.3.

Esterase 9 activity was detected in females and males from FUMOZ and FUZIM at every age examined between $2 \mathrm{~h}$ and 30 days (Figs. 1 and 3). The esterolytic activity of EST-9 in laboratory colonised and wild $A n$. funestus was at its maximum during the period that directly follows emergence (i.e., at 2 h) (Figs. 1 and 3 ). The fold decrease of EST-9 activity between $2 \mathrm{~h}$ and $8 \mathrm{~h}$ old FUMOZ females and males was 1.2 and 1.4 fold respectively. Furthermore, the EST-9 activity decreased in the FUMOZ An. funestus adults that were aged $2 \mathrm{~h}$ versus $24 \mathrm{~h}$ to 30 days by a range of 2.7 to 8.1 fold in the females and between 3.5 and 14.4 fold in the males. In the FUZIM adults, the EST-9 activity reduced by 1.2 and 1.3 fold in the females and males aged $2 \mathrm{~h}$ versus $8 \mathrm{~h}$. The fold decrease in EST-9 activity of FUZIM females and males aged $2 \mathrm{~h}$ versus $24 \mathrm{~h}$ to 15 days was between 1.4 and 5.9 fold in FUZIM females and between 1.5 and 7.8 fold in FUZIM males (Figs. 1 and 3).

\section{Discussion}

Nine specific esterases were evident in the An. funestus adults sampled regardless of whether their genotypes originated from southern Mozambique (FUMOZ) or Honde Valley, Zimbabwe (FUZIM). Of these esterases EST-1, -4 and -8 were classified as alpha esterases and EST-2, -3, -5,-6, - 7 and -9 as alpha-beta esterases based on their abilities to hydrolyse alpha- or beta-naphthyl acetate. Esterases 1 to 9 were further characterized according to inhibition criteria [13]. Esterases 1 and 8 were acetylesterases, as their activities were not inhibited by eserine sulphate, malathion or pHMB. Esterase 2 and 4 were arylesterases as they were only inhibited by pHMB. Esterases $-3,-5,-6$ and -7 , which likely have serine residues in their catalytic active sites, were inhibited by PMSF. Esterases $-5,-6$ and -7 were also inhibited by malathion and were therefore classified as carboxylesterases with a serine residue in the active site which is common in the carboxylesterases of insects. Since EST-3 activity was strongly inhibited only by PMSF and very slightly by $\mathrm{pHMB}$ but not by malathion or eserine sulphate, this esterase was considered to be an acetylesterase. Esterase 9 was classified as an acetylcholinesterase due to the strong inhibition of its activity by eserine sulphate. In several insect species, including An. gambiae Giles, there is an acetylcholinesterase with a cysteine residue near or at the rim of its active site, which is inhibited by sulphydryl reagents [25-27]. It is very likely that this is also the case for EST-9 in An. funestus.

The pattern of esterolytic activity of the esterases in An. funestus as well as information of these esterases in other members of the class Insecta may provide a clue as to their function. The variability observed in EST-1, EST-4, -5, -6, -7 and -8 could be due to the influence of external or environmental factors such as fluctuating temperature and humidity or could reflect the influence of the available food source on the expression and activity of these esterases. This suggests that during the lifespan of adult An. funestus these esterases play an important role in environmental adaptation. 
a.i.

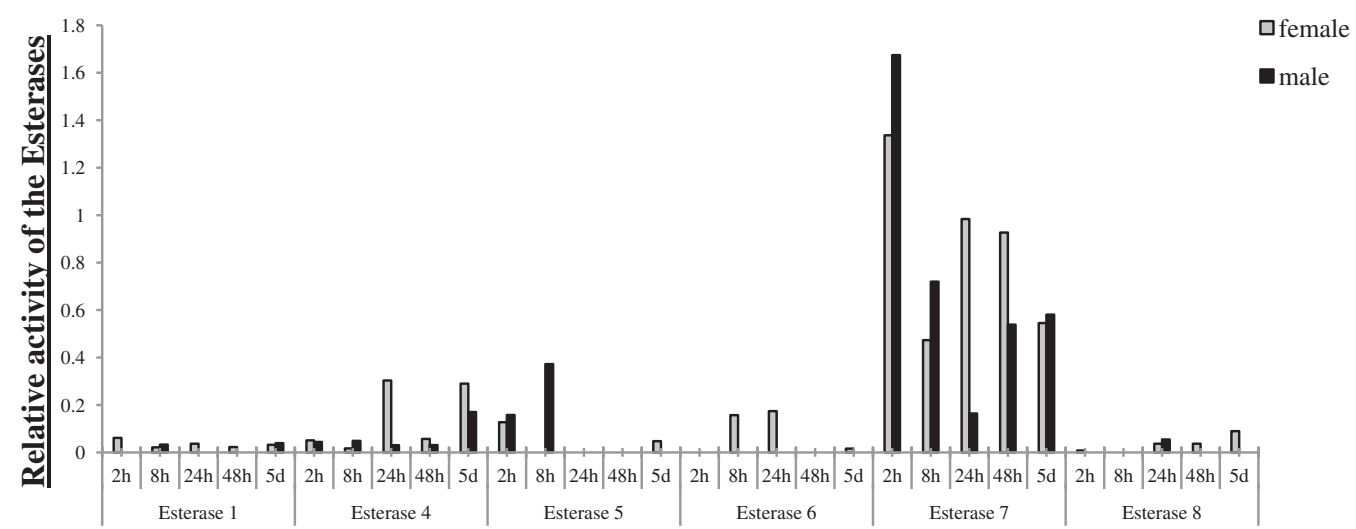

The activity of EST $-1,-4,-5,-6,-7$ and -8 in FUMOZ females and male aged 2 hours to 5 days post eclosion

a.ii.

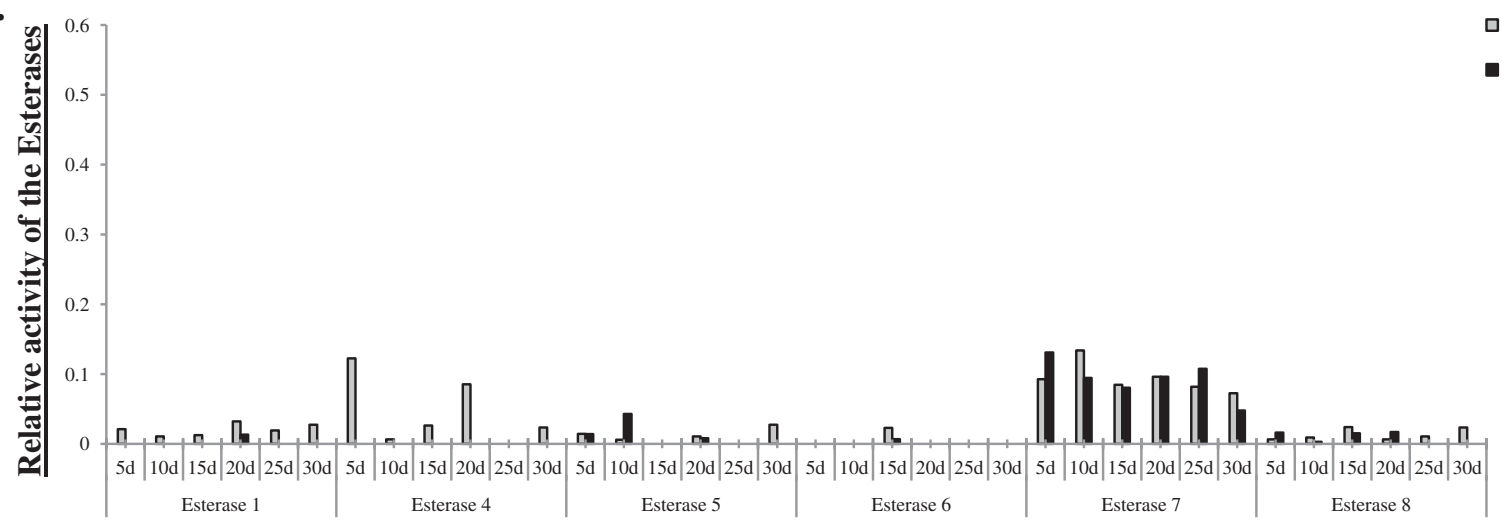

The activity of EST-1, $-4,-5,-6,-7$ and -8 in FUMOZ females and males aged 5 to 30 days post eclosion

b.

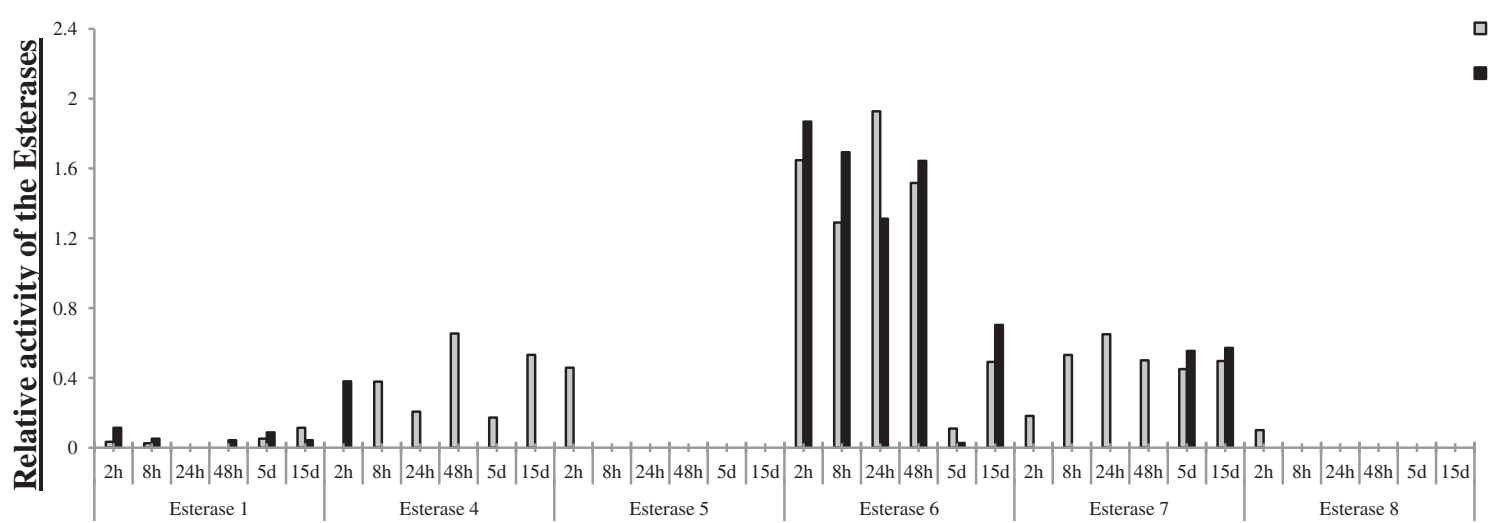

The activity of EST-1, $-4,-5,-6,-7$ and -8 in the FUZIM females and males aged 5 to 15 days post eclosion

Fig. 2 The activity of EST-1,-4,-5,-6,-7 and-8 in the adult An. funestus. a.i) FUMOZ female and males aged $2 \mathrm{~h}$ to 5 days post eclosion; a.ii) FUMOZ female and males 5 to 30 days post eclosion; b) FUZIM females and males aged $2 \mathrm{~h}$ to 15 days post eclosion. ( $h=$ hours old; $d=$ days old). The esterase activity was standardized according to the EST-9 activity observed in newly emerged $(2 \mathrm{~h})$ females in of the FUMOZ and FUZIM males, which was set at 1 fold 
a.i.

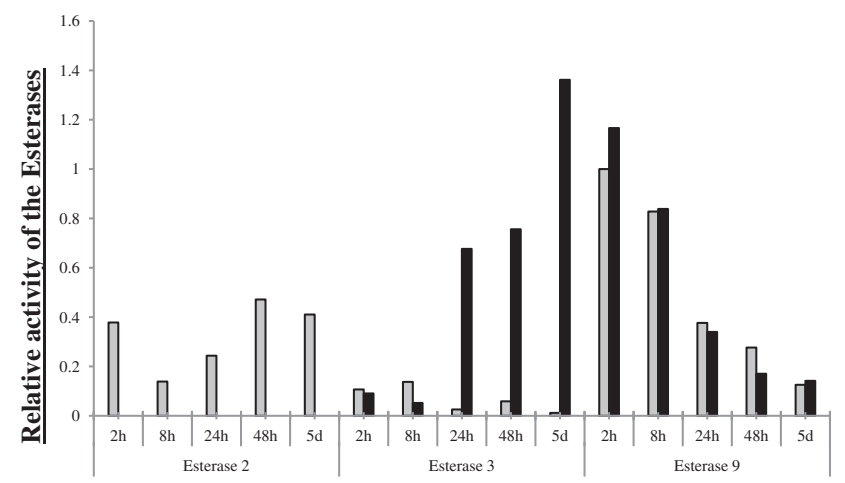

The activity of EST-2, -3 and -9 in the FUMOZ females and males aged 2 hours to 5 days post eclosion

a.ii.

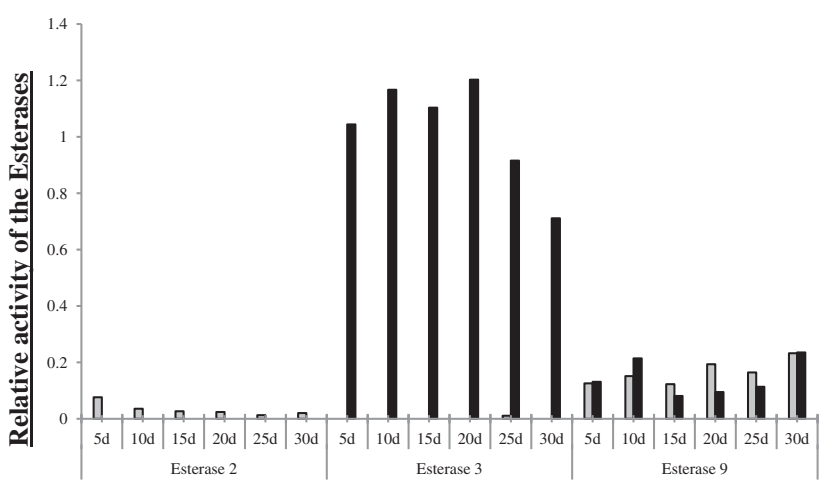

口female

- male

The activity of EST-2, -3 and -9 in the FUMOZ females and males aged 5 to 30 days post eclosion

b.

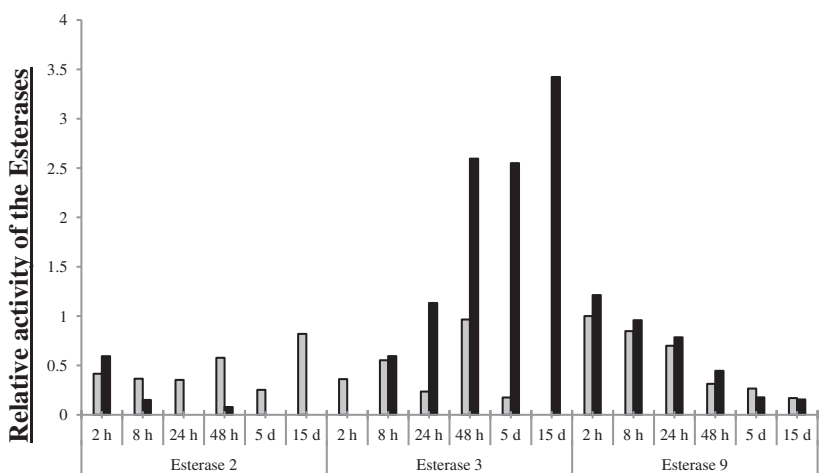

The activity of EST-2, -3 and -9 in the FUZIM females and males aged 2 hours to 15 days post eclosion

Fig. 3 The activity of EST-2,-3 and-9 in the adult An. funestus. a.i) FUMOZ female and males aged $2 \mathrm{~h}$ to 5 days post eclosion; a.ii) FUMOZ female and males 5 to 30 days post eclosion; b) FUZIM females and males aged $2 \mathrm{~h}$ to 15 days post eclosion. ( $h=$ hours old; $d=$ days old). The esterase activity was standardized according to the EST-9 activity observed in newly emerged ( 2 h) females in FUMOZ and FUZIM males, which was set at 1 fold

The An. funestus acetylcholinesterase EST-9 was present at all the ages in males and females from both the colonies, indicating that the activity of this esterase is essential during the adult life of An. funestus. In insects, acetycholinesterase activity is important for neurotransmission [28], coordination, locomotor activity and development [29, 30], longevity, female reproduction and growth of offspring [30], as well as for developing insecticide resistance [31]. It is very likely that EST-9 activity in An. funestus has similar roles to 
those in other insects, which would be necessary to maintain the normal physiological functions in the adult stage.

The An. funestus acetylesterases EST-1, -8 and -3 showed variable esterolytic activity patterns at different ages and sexes. Therefore it is probable that these esterases, which are responsible for the hydrolysis of acetic esters, each play different roles in An. funestus. Mateus et al. proposed that the acetylesterase (EST-4) in Drosophila species (D. mulleri, D. aldrichi, D. wheeleri, D. mojavensis, $D$. arizonae and $D$. navojoa) may act as juvenile hormone (JH) esterases (JHE) [32]. Juvenile hormone plays a significant role in male sexual development in insects and is important for male reproductive fitness [33], sexual signalling [34], male mating behaviour and protein synthesis in the male accessory glands [35]. Since EST-3 is an acetylesterase and has a male specific esterolytic activity pattern in An. funestus ([21], herein), it is possible that EST-3 has a JHE or JHE-like activity, which would regulate the $\mathrm{JH}$ expression level in An. funestus males.

The arylesterases, EST-2 and EST-4 also showed differential esterolytic activity patterns. Drosophila melanogaster transfected with the human paraoxonase (PON) 1 gene led to an increase of arylesterase activity in the PON1 transgenic flies, which also resulted in the protection of these flies from Pseudomonas aeruginosa induced lethality [36]. Pseudomonas species are present in the midgut of many mosquitoes, including Anopheles [37]. Therefore, it is possible that the arylesterases in $A n$. funestus may reduce the virulence of Pseudomonas species. Esterase-A (=arylesterase) was specifically found in the female salivary glands of An. stephensi Liston [38], supporting data presented here where EST-2 activity was predominantly higher in An. funestus females than males. If EST-2 is present only in the salivary glands of An. funestus females, it may further indicate an important role of this esterase during blood feeding or transmission of Plasmodium sporozoites. This needs to be further investigated.

The activities of carboxylesterases EST-5, -6 and EST-7 fluctuated in FUMOZ adults that were between $2 \mathrm{~h}$ and 30 days old and in FUZIM adults that were between $2 \mathrm{~h}$ and 15 days old. Carboxylesterases in other insects including Anopheles species play important roles in olfaction, behaviour, reproduction [7], insecticide resistance [39] pheromone degradation [40]. It is highly likely that these enzymes are involved in at least one of these functions. This would result in specific physiological changes that are necessary for important events during the lifespan of adult An. funestus.

\section{Conclusions}

We confirmed the presence of nine esterases characteristic to An. funestus adults as detected by IEE in a longestablished laboratory colony and a recent colony representing a wild An. funestus population. This is the first paper evaluating esterase activity over adult life span as well as the characterisation of esterase based on the inhibition criterion. Esterase-1 (acetylesterase),-4 (arylesterase),-5 (carboxylesterase),-6 (carboxylesterase),-7 (carboxylesterase) and-8 (acetylesterase) activities varied at different ages of adult An. funestus males and females and between colonies. Esterase-2 (arylesterase) and-3 (acetylesterase) activities at different ages were most pronounced in females and males respectively. Esterase-9 (acetylcholinesterase) activity was evident at the different ages in males and females.

The information from this study provides a stepping stone towards understanding enzyme-mediated physiological processes in adult An. funestus based on the esterase enzymes that are involved. Future studies regarding the activities of the esterases in An. funestus adults can be used to determine the structure and function of these esterases. Ultimately, these esterases could serve as valuable tools in understanding the biology of this species, which is essential for effective control of this major African malaria vector.

\section{Abbreviations}

DDT: Dichlorodiphenyltrichloroethane; EST: Esterase; FUMOZ: An. funestus colony originating from Mozambique; FUZIM: Wild-caught An. funestus from Zimbabwe; IEE: Isoenzyme electrophoresis; JH: Juvenile hormone; JHE: Juvenile hormone esterase; NICD: National Institute of Communicable Diseases; pHMB: p-hydroxymercuribenzoic acid sodium salt; pMSF: Phenylmethylsulfonyl fluoride; PON: Paraoxonase; TBE: Tris-Boric acid-EDTA.

\section{Competing interests}

The authors declare that they have no competing interests.

\section{Authors' contributions}

YD carried out the study design, molecular experiments and analysed the data. LK contributed to the study design and data analysis. Both authors contributed to drafting the final manuscript. Both authors read and approved the final manuscript.

\section{Acknowledgements}

This work was supported by the Department of Science and Technology (DST)/National Research Foundation (NRF) Professional Development Programme (PDP) to LLK; DST/NRF Research Chair Initiative grant to Prof. M. Coetzee, National Research Foundation Incentive Funding ((UID) 85538) to LLK. The Grantholders acknowledges that opinions, findings and conclusions or recommendations expressed in any publication generated by the NRF supported research are that of the author(s), and that the NRF accepts no liability whatsoever in this regard. The wild Zimbabwe material was collected as part of an $\mathrm{NIH}$ International Centre of Excellence for Malaria Research (ICEMR) grant to the Johns Hopkins Malaria Research Institute (grant no. U19 Al089680). Profs. R.H. Hunt and M. Coetzee and the field teams of the Zimbabwe Biomedical Research \& Training Institute (Drs. S. Mharakurwa and S. Munyati) and the National Institute for Health Research (Dr. S. Mutambu and Mr. A. Makuwaza), are thanked for providing the material. We are thankful to Profs. M. Coetzee and B. Brooke for comments on the manuscript.

Received: 4 September 2015 Accepted: 11 February 2016

Published online: 27 February 2016

\section{References}

1. WHO. World Malaria Report 2015. http://www.who.int/malaria/publications/ world-malaria-report-2015/report/en/. Accessed 10 February 2016. 
2. Hargreaves K, Koekemoer LL, Brooke BD, Hunt RH, Mthembu J, Coetzee M. Anopheles funestus resistant to pyrethroid insecticides in South Africa. Med Vet Entomol. 2000;14:181-9.

3. Sinka ME, Bangs MJ, Manguin S, Rubio-Palis Y, Chareonviriyaphap T, Coetzee M, et al. A global map of dominant malaria vectors. Parasit Vectors. 2012;5:69.

4. Coetzee M, Fontenille D. Advances in the study of Anopheles funestus, a major vector of malaria in Africa. Insect Biochem Mol Biol. 2004;34:599-605.

5. Coetzee M, Koekemoer LL. Molecular systematics and insecticide resistance in the major African malaria vector Anopheles funestus. Annu Rev Entomol. 2013;58:393-412

6. Choi KS, Christian R, Nardini L, Wood OR, Agubuzo E, Muleba M, et al. Insecticide resistance and role in malaria transmission of Anopheles funestus populations from Zambia and Zimbabwe. Parasit Vectors. 2014;7:464.

7. Chertemps T, François A, Durand N, Rosell G, Dekker T, Lucas P, et al. A carboxylesterase, Esterase-6, modulates sensory physiological and behavioral response dynamics to pheromone in Drosophila. BMC Biol. 2012;10:56.

8. Briegel $H$, Freyvogel TA. Non-specific esterases during development of Culicine mosquitoes. Acta Trop. 1971;28:291-7.

9. Rodriguez GA, dos Santos JM, Maia J, de F. Ontogenetic patterns and genetic variation in Anopheles (Anopheles) intermedius Chagas, 1908 and Anopheles (Anopheles) mattogrossensis Lutz \& Neiva, 1911 (Diptera: Culicidae) in the Brazilian amazon. Rev Bras Biol. 2000;60:341-51.

10. Browder MH, D'Amico $\sqcup$, Nijhout HF. The role of low levels of juvenile hormone esterase in the metamorphosis of Manduca sexta. J Insect Sci. 2001;1:11.

11. Sahgal A, Kumar S, Pillai MKK. Microplate assay of elevated esterase activity in individual pyrethroid-resistant mosquitoes. J Biosci. 1994;19:193-9.

12. Alizadeh $M$, Bandani $A R$, Amiri A. Evaluation of insecticide resistance and biochemical mechanism in two populations of Eurygaster integriceps puton (Heteroptera: Scutelleridae). Mun Ent Zool. 2010;5:734-44.

13. Montella IR, Schama R, Valle D. The classification of esterases: an important gene family involved in insecticide resistance-a review. Mem Inst Oswaldo Cruz. 2012;107:437-49.

14. Gilbert DG, Richmond RC. Esterase 6 in Drosophila melanogaster: reproductive function of active and null males at low temperature. Proc Natl Acad Sci U S A. 1982;79:2962-6.

15. Baffi MA, Pereira CD, de Souza GRL, Ceron CR, Bonetti AM. Esterase profile in the postembryonic development of Rhipicephalus microplus. Pesq Agropec Bras. 2007:42:1183-8.

16. Djouaka R, Irving H, Tukur Z, Wondji CS. Exploring mechanisms of multiple insecticide resistance in a population of the malaria vector Anopheles funestus in Benin. PLoS One. 2011;6:e27760.

17. Booth GM, Connor J, Metcalf RA, Larsen JR. A comparative study of the effects of selective inhibitors on esterase isozymes from the mosquito Anopheles punctipennis. Comp Biochem Physiol B. 1973;44:1185-95.

18. Crews-Oyen AE, Kumar V, Collins FH. Association of two esterase genes, a chromosomal inversion, and susceptibility to Plasmodium cynomolgi in the African malaria vector Anopheles gambiae. Am J Trop Med Hyg. 1993;49:341-7.

19. Cuamba N, Morgan JC, Irving H, Steven A, Wondji CS. High level of pyrethroid resistance in an Anopheles funestus population of the Chokwe District in Mozambique. PLoS One. 2010;5:e11010.

20. Wondji CS, Coleman M, Kleinschmidt I, Mzilahowa T, Irving H, Ndula M, et al. Impact of pyrethroid resistance on operational malaria control in Malawi. Proc Natl Acad Sci U S A. 2012;109:19063-70.

21. Green CA. A sex-limited esterase in the accessory glands of males of Anopheles funestus. Mosquito News. 1977;37:46-8.

22. Hunt RH, Brooke BD, Pillay C, Koekemoer LL, Coetzee M. Laboratory selection for and characteristics of pyrethroid resistance in the malaria vector Anopheles funestus. Med Vet Entomol. 2005;19:271-5.

23. Koekemoer LL. Systematic studies on the Anopheles funestus (Diptera: Culicidae) group in Southern Africa. PhD Thesis. Johannesburg: The University of the Witwatersrand; 1999

24. Rasband WS, ImageJ. [http://imagej.nih.gov/ij/]. Website U. S. National Institutes of Health, Bethesda, Maryland, USA; 1997-2015

25. Pang YP. Novel acetylcholinesterase target site for malaria mosquito control. PLoS One. 2006;20:e58

26. Pang YP, Brimijoin S, Ragsdale DW, Zhu KY, Suranyi R. Novel and viable acetylcholinesterase target site for developing effective and environmentally safe insecticides. Curr Drug Targets. 2012;13:471-82.

27. Dou D, Park JG, Rana S, Madden BJ, Jiang H, Pang YP. Novel selective and irreversible mosquito acetylcholinesterase inhibitors for controlling malaria and other mosquito-borne diseases. Sci Rep. 2013;3:1068.
28. Fukuto TR. Mechanism of action of organophosphorus and carbamate insecticides. Environ Health Perspect. 1990;87:245-54.

29. Incardona JP, Rosenberry TL. Replacement of the glycoinositol phospholipid anchor of Drosophila acetylcholinesterase with a transmembrane domain does not alter sorting in neurons and epithelia but results in behavioral defects. Mol Biol Cell. 1996;7:613-30.

30. Lu Y, Park Y, Gao X, Zhang X, Yao J, Pang YP. Cholinergic and noncholinergic functions of two acetylcholinesterase genes revealed by genesilencing in Tribolium castaneum. Sci Rep. 2012;2:288.

31. Casimiro S, Coleman M, Mohloai P, Hemingway J, Sharp B. Insecticide resistance in Anopheles funestus (Diptera: Culicidae) from Mozambique. J Med Entomol. 2006:43:267-75.

32. Mateus RP, Machado LPB, Ceron CR. Gene duplication and subsequent differentiation of esterases in cactophilic Drosophila species. Chapter 19. In: Friedberg F, editor. Gene duplication. Book 2. Rijeka: InTech; 2011. p. 353-72.

33. Parthasarathy R, Tan A, Sun Z, Chen Z, Rankin M, Palli SR. Juvenile hormone regulation of male accessory gland activity in the red flour beetle Tribolium castaneum. Mech Dev. 2009;126:563-79.

34. Teal PE, Gomez-Simuta Y, Proveaux AT. Mating experience and juvenile hormone enhance sexual signaling and mating in male Caribbean fruit flies. Proc Natl Acad Sci U S A. 2000;97:3708-12.

35. Wilson TG, DeMoor S, Lei J. Juvenile hormone involvement in Drosophila melanogaster male reproduction as suggested by the Methoprenetolerant(27) mutant phenotype. Insect Biochem Mol Biol. 2003;33:1167-75.

36. Stoltz DA, Ozer EA, Taft PJ, Barry M, Liu L, Kiss PJ, et al. Drosophila are protected from Pseudomonas aeruginosa lethality by transgenic expression of paraoxonase-1. J Clin Invest. 2008;118:3123-31.

37. Manguin S, Ngo CT, Tainchum K, Juntarajumnong W, Chareonviriyaphap T, Michon AL, et al. In: Manguin S, editor. Bacterial biodiversity in midguts of Anopheles mosquitoes, malaria vectors in Southeast Asia. Rijeka: InTech; 2013. p. 549-76. Chapter 18.

38. Poehling HM, Meyer W. Esterases and glycoproteins in the salivary glands of Anopheles stephensi. Insect Biochem. 1980;10:189-98.

39. Gong YH, Yu XR, Shang QL, Shi XY, Gao XW. Oral delivery mediated RNA interference of a carboxylesterase gene results in reduced resistance to organophosphorus insecticides in the cotton Aphid Aphis gossypii Glover. PLoS One. 2014;9:e102823.

40. Durand N, Chertemps T, Maïbèche-Coisne M. Antennal carboxylesterases in a moth, structural and functional diversity. Commun Integr Biol. 2012;5:284-6.

\section{Submit your next manuscript to BioMed Central and we will help you at every step:}

- We accept pre-submission inquiries

- Our selector tool helps you to find the most relevant journal

- We provide round the clock customer support

- Convenient online submission

- Thorough peer review

- Inclusion in PubMed and all major indexing services

- Maximum visibility for your research

Submit your manuscript at www.biomedcentral.com/submit
Biomed Central 